\title{
As mulheres na \\ pesquisa, no desenvolvimento tecnológico e na inovação: uma comparação Brasil/França
}

Jacqueline Leta, Martine Carisey,

Patrick Séchet e Pierre Ohayon

\section{Introdução}

On ne nait pas femme, on le devient* Simone de Beauvoir A vida não espera

Pearl Buck (Prêmio Nobel de Literatura,1938)

Historicamente, a atividade que conhecemos hoje como ciência sempre foi apontada como predominantemente realizada por homens. Foram homens os principais pensadores e filósofos da Grécia Antiga, berço da ciência moderna ocidental; na Idade Média, a alquimia, prática comum nesse período da história e precursora da química moderna, também teve nos homens seus representantes mais ilustres. Nos séculos XV e XVI, marcados por eventos e mudanças significativas na sociedade, que possibilitaram o surgimento da ciência moderna, esse cenário pouco mudou. O que se observa é que, quando estavam envolvidas nessa atividade, as mulheres, principalmente as da aristocracia, exerciam papéis de interlocutoras e de tutoras de renomados filósofos ora cuidando, por exemplo, das coleções ora 
ilustrando ou traduzindo experimentos e textos. A criação de academias e sociedades científicas no século XVII deu à então recémsurgida ciência moderna um caráter institucional, favorecendo seu desenvolvimento. Esse novo espaço, no qual ocorriam intensas e calorosas discussões, não permitia, no entanto, o acesso de mulheres. Duzentos anos depois, ao abrigar essa atividade, as universidades européias, inicialmente as alemãs, ganham destaque não apenas pela produção cada vez maior de conhecimento por mulheres, mas também por reproduzir uma atividade dominada por homens ${ }^{1}$.

A participação mais efetiva de mulheres no meio científico inicia-se do século XX e o reconhecimento e premiação dos estudos da cientista Marie Curie na França pode ser considerado um marco neste processo. Mas é após a Segunda Guerra Mundial que as mulheres entram definitivamente nessa atividade. A necessidade de mão-de-obra qualificada para áreas e setores estratégicos, tal como a científica, e os movimentos feministas estimulam e exigem a entrada das mulheres na universidade e nos centros de pesquisa, assim como no mercado de trabalho.

A despeito das mudanças recentes e significativas no acesso das mulheres à educação e às atividades de ciência e tecnologia (C\&T), essa temática tem ainda merecido muito interesse, seja por parte da comunidade acadêmica, seja pelo poder público. Tal interesse deve-se, principalmente, ao fato de que, apesar de estarem bem representadas em alguns setores e profissões (saúde, educação, entre outras), as mulheres ainda estão sub-representadas em muitas outras, tal como nas atividades de C\&T. Um sistema de C\&T consolidado, fundamental e estratégico no cenário mundial atual, no qual os países precisam ser mais competitivos - individualmente ou em grupos - para ganhar novos mercados, só se fortalece por meio da qualificação e diversificação de todos os seus elementos. Pensar na participação de mulheres na ciência (ou em qualquer outra atividade) é, sem dúvida, ampliar o espectro de sua diversidade. Muitos governos já se deram conta disso e têm garantido e/ou estimulado a inserção de mulheres em atividades, a partir de políticas públicas específicas.

O presente estudo analisa e compara o espaço conquistado pelas mulheres nas atividades de C\&T em dois países, França e Brasil, que diferem não apenas nas dimensões demográficas e econômicas, mas também em suas tradições científicas. Assim, as respectivas estatísticas, bem como as ações e medidas legislativas para estimular a inserção de mulheres na atividade científica, são apresentadas, discutidas e contextualizadas à luz da história de institucionalização da ciência nos dois países.

\section{A tradição científica francesa e a recente ciência no Brasil: marcos da institucionalização}

A ciência moderna é uma atividade recente na história da humanidade. Muitos autores apontam o Renascimento como um dos marcos para o seu surgimento. Esse e outros eventos (as grandes navegações e a reforma protestante, por exemplo) mudaram conceitos e alteraram profundamente o papel social de algumas instituições, tal como o poder da Igreja. Estimularam também novas práticas entre os filósofos naturalistas, o que causou impacto direto na geração de novos conhecimentos, tendo a matemática em sua base metodológica. Tais mudanças foram decisivas para estimular a população a fazer parte dessa atividade em pleno processo de transformação, as ciências. 
Em meio a essas mudanças do século XVI, destacam-se, entre os importantes nomes da França, Ambroise Pare (15171590), que se dedicou aos estudos de medicina e René Descartes (1596-1650), filósofo, fisiologista e matemático que publicou uma das principais obras da ciência moderna, Discours de la méthode pour bien conduire sa raison et chercher la vérité dans les sciences. Um século depois, são inúmeros os expoentes experimentalistas na França: Buffon (1707-1788), que teve a intuição da evolução das espécies e da transformação do universo; Messier (1730-1817), astrônomo que descobriu um número significativo de cometas (Halley entre outros); Lagrange (1736-1813), astrônomo e matemático com considerável obra científica (notavelmente sobre o cálculo das variações, as funções derivadas); Coulomb (1736-1806), físico que descobriu a lei que leva seu nome em eletroestática e magnetismo; Haüy (1743-1822), um dos criadores da cristalografia; Lavoisier (1743-1794), um dos criadores da química moderna, conhecido em especial pelos estudos sobre a composição do ar; e Louis Pasteur (1822-1895), renomado em particular pelos seus estudos sobre fermentação e vacina contra a raiva. A França foi pioneira também na edição de revistas científicas: o periódico Le Journal des Sçavans, publicado em Paris em 1665 foi o primeiro a prover informações regulares sobre a ciência, disseminando relatos de experimentos e observações em física, química, anatomia e meteorologia. Associada a essa nova prática, a França (assim como a Inglaterra, poucos anos antes) inova ao fundar sua Académie des Sciences, em 1666, que representou a primeira forma organizacional dessa atividade social ainda em transformação. Pouco tempo depois, com a implementação da ciência como parte integrante do modelo de organização acadêmica da recém-criada Ecole Polytechnique (1795), a França novamente dá um passo adiante. Esse modelo aos poucos dissipou-se pelas instituições daquele país, que, no século XIX, já apresentava um sistema acadêmico unificado de universidades e instituições voltadas aos mais diferentes ofícios, situadas principalmente ao redor de Paris (BEN-David, 1960).

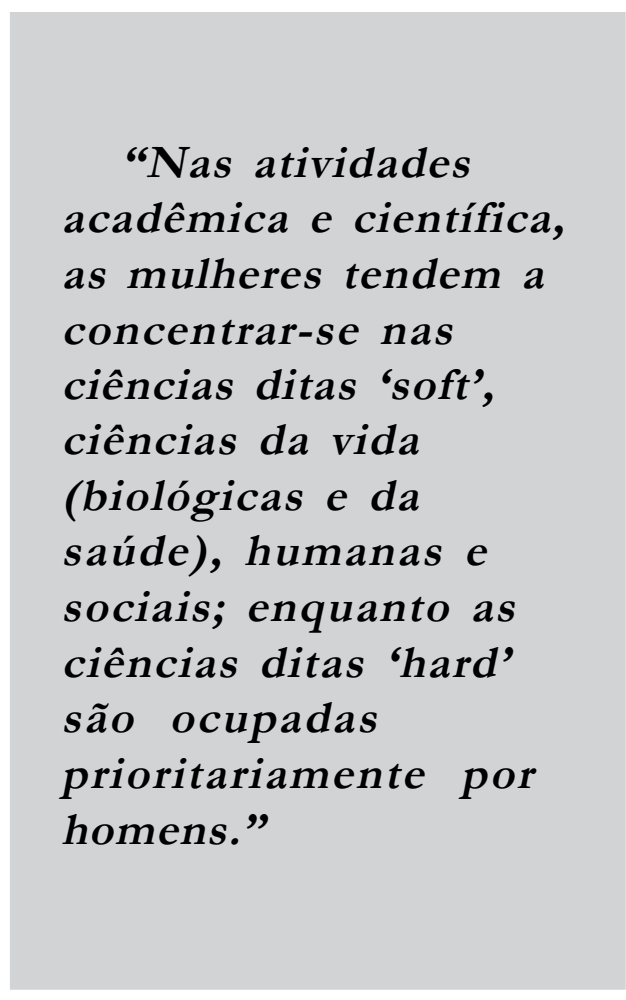

Diferente do que ocorreu na França, a institucionalização da ciência no Brasil deu-se há pouco mais de um século. Stepan (1976) e Schwartzman (1978), entre outros, descrevem como possíveis fatores para o atraso da institucionalização da ciência brasileira: 1) a política econômico-cultural imposta por Portugal ao Brasil, que, além de restringir a troca com outros países, permitia somente a criação de instituições indispensáveis para a manutenção de suas 
atividades exploratórias no território; 2) a falta de rompimento definitivo com as tradições da colônia; e 3) a pouca tradição científica de Portugal.

No século XVI, os naturalistas no Brasil eram exploradores e colonos que estudavam a flora e a fauna do território brasileiro. Uma das primeiras publicações (científicas) brasileiras foi a Historia naturalis brasiliae, de 1648, escrita por um dos tantos holandeses que povoaram o Nordeste brasileiro nesse período. $\mathrm{O}$ intercâmbio entre os naturalistas brasileiros e europeus favoreceu a criação de sociedades científicas no Brasil, como a Sociedade Científica do Rio de Janeiro, fundada em 1772. Mas foi a vinda da família real ao Brasil, em 1808, que transformou as estruturas sociais, econômicas e culturais no País. Graças ao entusiasmo do Rei de Portugal Dom João VI, diversas instituições de pesquisa foram fundadas durante o período em que esteve à frente do comando do Império no Brasil, com destaque para o Museu Nacional, criado em 1818, com o nome de Museu Real.

No início do século XX, a ciência moderna já estava consolidada e institucionalizada na França, enquanto, no Brasil, essa atividade era ainda resultado de esforço individual, da educação européia e, em muitos casos, da fortuna pessoal do cientista. O exemplo mais importante foi o de Oswaldo Cruz, que fundou, em 1900, aquela que é considerada a primeira instituição de reconhecimento científico, inclusive internacional, o Instituto de Soroterapia de Manguinhos, que, posteriormente, recebeu o nome de Instituto Oswaldo Cruz (IOC), hoje uma das unidades técnico-científicas da Fundação Oswaldo Cruz (Fiocruz), localizada na cidade do Rio de Janeiro.

Vale destacar que, até o início do século $\mathrm{XX}$, não havia no País nenhuma universidade. O ensino superior estava nas mãos de poucas faculdades, principalmente relacionadas à formação em medicina e em direito. A primeira, a Universidade do Brasil (hoje Universidade Federal do Rio de Janeiro), foi fundada em 1920, mas não representou ganho real, naquele momento, para a comunidade científica brasileira, pois tratou-se apenas de uma fusão de escolas e unidades já existentes na cidade. O ganho só ocorreu em 1934, com a fundação da Universidade de São Paulo, primeira universidade brasileira que, desde a sua concepção, teve a ciência como um de seus pilares.

A partir da década de 50, ocorreu um aumento no número de cientistas no Brasil, e a criação das primeiras agências de fomento de ciência no País, em 1951, mudou o rumo dessa atividade. $\mathrm{Na}$ década seguinte, os programas de pós-graduação que existiam foram reestruturados, e o Ministério de Educação promoveu a criação oficial dos cursos de pós-graduação em todo o País. Esses dois eventos - a criação das agencias de fomento e dos programas de pós-graduação - foram decisivos para a consolidação do sistema de C\&T encontrado no País hoje.

\section{A mulher no mercado de trabalho e na educação}

O acesso ao mercado de trabalho para as mulheres é recente. Apesar das diferenças observadas entre Brasil e França (Tabela 1), Teixeira (2004) acredita que "as desigualdades vividas no quotidiano da sociedade, no que se refere às relações de gênero, não se definiram a partir do econômico, mas, especialmente a partir do cultural e do social", não tendo, portanto relação com a tradição científica. Segundo os dados do Instituto Brasileiro de Geografia e Estatística (IBGE, 2004), no período pós-Segunda Guerra Mundial, as mulheres representavam menos 


\section{Tabela 1: Participação de mulheres na economia}

\begin{tabular}{l|c|c|c|c|c}
\hline \multicolumn{2}{l}{$\begin{array}{l}\text { População Economicamente } \\
\text { Ativa no Brasil }\end{array}$} & \multicolumn{3}{c}{$\begin{array}{c}\text { População Economicamente } \\
\text { Ativa na França*** }\end{array}$} \\
\hline Ano & Total & $\%$ Mulher & Ano & Total & $\%$ mulher \\
\hline $1950^{*}$ & 17.117 .362 & 14,6 & 1950 & ND & ND \\
\hline $1960^{*}$ & 22.651 .263 & 17,9 & 1960 & ND & ND \\
\hline $1970^{*}$ & 29.557 .224 & 20,9 & 1970 & 22.128 .000 & 36,47 \\
\hline $1997 * *$ & 75.213 .283 & 31,0 & 1997 & 26.108 .000 & 44,90 \\
\hline 1998 & 76.885 .732 & 40,67 & & & \\
\hline 1999 & 79.315 .287 & 41,39 & & & 45,38 \\
\hline 2000 & ND & ND & 2000 & 26.487 .000 & ND \\
\hline 2001 & 83.951 .777 & 41,9 & 2001 & ND & 45,65 \\
\hline 2002 & 86.917 .348 & 42,5 & 2002 & 27.198 .000 & 45,90 \\
\hline 2003 & 88.803 .481 & 42,7 & 2003 & 27.371 .000 & 46,18 \\
\hline 2004 & 91.035 .164 & 43,3 & 2004 & 27.518 .000 & 46,36 \\
\hline 2005 & ND & ND & 2005 & 27.639 .000 & \\
\hline
\end{tabular}

Fonte: Brasil: * Os dados de 1950, 60 e 70 referem-se à PEA com 10 anos ou mais;

** Os dados de 1997 referem-se à PEA de 10 a 24 anos. $^{2}$ Os dados de 2002, 2003 e 2004 referem-se a população economicamente ativa com 10 ou mais anos de idade.

França: *** Os dados apontados referem-se à França metropolitana (não abrangendo os territórios franceses situados em outros continentes) ${ }^{3}$. Dados obtidos do (INSEE), em www.insee.fr. Acesso em 6/12/ 2006; ND = Não disponível.

de $15 \%$ da população economicamente ativa (PEA) do Brasil. Essa fração cresceu lentamente até os anos 70, mas, depois disso, em pouco menos de três décadas, as mulheres passaram a representar pouco mais de 30\% da PEA. Na França, a PEA cresceu, em valor absoluto, aproximadamente 14\% no período de 1970 a 2000, mas esse fenômeno ocorreu de forma gradativa e lenta. Por outro lado, é possível observar que essa expansão sucedeu-se de forma mais agressiva no Brasil: cerca de $50 \%$ no período de 1970 a 1997.

No Brasil, a entrada de mulheres no mercado de trabalho foi acompanhada por um aumento no seu nível de escolarização. Dados do IBGE mostram que a taxa de alfabetização de mulheres com mais de 15 anos cresceu de $72,9 \%$, em 1980, para $86,5 \%$, em 2000. Esse dado é reflexo do aumento, cada vez maior, da entrada de mulheres no sistema educacional brasileiro. No final dos anos 90, as mulheres brasileiras passaram a ser maioria no ensino médio e no ensino universitário (Tabela 2).

$\mathrm{Na}$ França, embora o nível de escolarização seja relativamente elevado e o analfabetismo praticamente nulo, a inserção de mulheres no mercado de trabalho mostra semelhanças com os dados brasileiros (Tabela 2). Assim como no Brasil, o crescimento e a modernização do setor produtivo, a migração e intensificação das atividades econômicas 
nas cidades e o dinamismo dos movimentos femininos asseguraram às mulheres maior espaço nos postos de trabalho. É interessante notar, na Tabela 2 , que, à medida que a escolaridade aumenta, em ambos os países, a presença das mulheres cresce significativamente. No ensino superior, a participação das mulheres é um pouco maior no Brasil do que na França (56,35\% contra 55,6\%). Em ambos os países, o maior nível de escolarização assegura concurso daquele ano teve como primeiro colocado ("major" da EP) uma moça, Anne Chopinet. Na ocasião, esse acontecimento foi manchete dos jornais na França 5 . Esse fato mostra como, até na era contemporânea, as mulheres ainda são excluídas da formação de elite e dos treinamentos nas politécnicas, instituições de alto reconhecimento na França, amplamente requisitadas por setores voltados às altas tecnologias e aos mercados globalizados.

Tabela 2: Matrículas de mulheres no sistema educacional (em \%)

\begin{tabular}{|c|c|c|c|c|c|c|}
\hline \multicolumn{4}{|c|}{ Brasil* } & \multicolumn{3}{|c|}{ França } \\
\hline Nível & Ano & $\begin{array}{l}\text { Total de } \\
\text { estudantes }\end{array}$ & $\%$ mulheres & Ano & $\begin{array}{l}\text { Total de } \\
\text { estudantes }\end{array}$ & $\%$ mulheres \\
\hline \multirow{4}{*}{$\begin{array}{l}\text { Ensino } \\
\text { Fundamental }\end{array}$} & 1970 & 12.812 .029 & 49,71 & $1970 / 71$ & 7.219 .900 & ND \\
\hline & 1999* & 33.030 .081 & 49,05 & & & \\
\hline & & & & $2002 / 03$ & 6.529 .193 & 48,7 \\
\hline & 2004 & 32.496 .011 & 48,77 & $2004 / 05$ & 6.585 .500 & ND \\
\hline \multirow{4}{*}{$\begin{array}{l}\text { Ensino } \\
\text { Médio }\end{array}$} & 1970 & 1.897 .893 & 49,36 & $1970 / 71$ & 4.452 .100 & ND \\
\hline & 1999* & 7.976 .273 & 55,27 & & & \\
\hline & & & & $2002 / 03$ & 4.788 .397 & 51,1 \\
\hline & 2004 & 8.744 .495 & 54,23 & $2004 / 05$ & 5.540 .300 & ND \\
\hline \multirow{4}{*}{$\begin{array}{l}\text { Ensino } \\
\text { Superior }\end{array}$} & & & & $1970 / 71$ & 850.600 & ND \\
\hline & 1972 & 478.184 & 46,6 & & & \\
\hline & 2002 & 3.479 .913 & 56,5 & 2002 & 2.209 .000 & 55,5 \\
\hline & 2004 & 4.163 .733 & 56,35 & $2004 / 05$ & 2.269 .800 & 55,6 \\
\hline
\end{tabular}

Fonte: *1999 - Estatísticas do Século XX (IBGE, 2002) ${ }^{6}$;

**2002 e 2004 - Sinopse do Ensino Superior (INEP) ${ }^{7}$. Dados da França: Ministère de l'Éducation Nationale, de la Recherche et de la Technologie ${ }^{8}$. ND = Não disponível.

maior oportunidade de inserção no mercado de trabalho.

$\mathrm{O}$ acesso à École Polytechnique (EP) ${ }^{4}$, marco da institucionalização da ciência na França, só foi permitido às mulheres a partir de 1972. Fato interessante é que o

\section{A mulher na ciência e o teto de cristal}

No século XX, a necessidade de mãode-obra qualificada para a atividade científica e os movimentos feministas 
estimularam a inserção de mulheres na ciência. No Brasil, havia, no ano de 1972, 121 mulheres matriculadas nos cursos de doutorado no Brasil, que representavam $20,5 \%$ do total de estudantes matriculados em todo o País?. Três décadas depois, a fração de mulheres que recebem bolsas de estudo, concedidas pelo Conselho Nacional de Desenvolvimento Científico e Tecnológico (CNPq), nos cursos de doutorado chega próximo de 50\%, enquanto na modalidade anterior, bolsas de mestrado, elas já superaram os homens (Tabela 3).

Tabela 3: As mulheres brasileiras e francesas no atual sistema de ciência, tecnologia e inovação

\begin{tabular}{|c|c|c|c|c|c|}
\hline \multicolumn{3}{|c|}{ Brasil } & \multicolumn{3}{|c|}{ França } \\
\hline Bolsa / cargos & Total $\left(^{*}\right)$ & $\%$ mulheres & Bolsas / cargos & Total (*) & $\%$ mulheres \\
\hline $\begin{array}{l}\text { Bolsa CNPq (1): } \\
\text { - Graduação } \\
\text { - Mestrado }\end{array}$ & 14.040 & 55,10 & $\begin{array}{l}\text { Bolsas/2000 (Ministério } \\
\text { da pesquisa) (6) } \\
\text { ND }\end{array}$ & $\begin{array}{l}3.900 \\
\text { ND }\end{array}$ & $\begin{array}{l}39,6 \\
\text { ND }\end{array}$ \\
\hline 2002 & 5.592 & 52,87 & ND & ND & ND \\
\hline $\begin{array}{l}2004 \\
\text { - Doutorado }\end{array}$ & 7.154 & 51,41 & ND & ND & ND \\
\hline 2002 & 5.734 & 48,38 & ND & ND & ND \\
\hline $\begin{array}{l}2004 \\
\text { - Produtividade } \\
\text { em Pesquisa }\end{array}$ & 6.826 & 48,93 & ND & ND & ND \\
\hline $\begin{array}{l}2002 \\
2004\end{array}$ & $\begin{array}{l}7.763 \\
8.815\end{array}$ & $\begin{array}{l}32,25 \\
33,28\end{array}$ & $\begin{array}{l}\text { ND } \\
\text { ND }\end{array}$ & $\begin{array}{l}\text { ND } \\
\text { ND }\end{array}$ & $\begin{array}{l}\text { ND } \\
\text { ND }\end{array}$ \\
\hline $\begin{array}{l}\text { Pesquisadores- } \\
\text { líderes ( } 2 \text { ) }\end{array}$ & 21.062 & 40,7 & $\begin{array}{l}\text { Professores titulares de } \\
\text { universidades e IPs ( } 7 \text { ) }\end{array}$ & 23.847 & 17,3 \\
\hline $\begin{array}{l}\text { Pesquisadores } \\
\text { em comitês } \\
\text { científicos }(3)\end{array}$ & & & $\begin{array}{l}\text { Membros de comitês } \\
\text { científicos (8) }\end{array}$ & & \\
\hline 2004 & 195 & 22,1 & & & \\
\hline 2006 & 236 & 22,8 & & 831 & 26,1 \\
\hline $\begin{array}{l}\text { Cargos de chefia } \\
\text { na UFRJ (4) }\end{array}$ & 96 & 24,0 & & & \\
\hline $\begin{array}{l}\text { Membros titulares } \\
\text { da Academia } \\
\text { Brasileira de } \\
\text { Ciências (5) }\end{array}$ & & & $\begin{array}{l}\text { Academia de } \\
\text { Ciências (9) }\end{array}$ & & \\
\hline 2004 & 353 & 7,4 & & & \\
\hline 2006 & 619 & 11 & & 484 & 5,1 \\
\hline
\end{tabular}

Fonte: Brasil: (1) CNPq, Estatísticas de Bolsas (2002 e 2004); (2) CNPq, Diretório de Grupos de Pesquisa (2002); (3) CNPq, Composição dos Comitês de Assessoramento do CNPq (2004 e 2006); (4) SIGMAUFRJ, docentes com cargos de chefia em 2004; (5) ABC - Academia Brasileira de Ciências (2004 e 2006) ${ }^{10}$; França: (6) São bolsas anuais alocadas para pesquisa; (7) IPs = Institutos de Pesquisa; (8) Membros junto ao Ministério da Pesquisa (Diretoria da Pesquisa); (9) Dados de 2004; (10) Dados de 2004.

(*) Total homens + mulheres; ND = Não disponível. 
Muito embora as estatísticas apontem nitidamente uma mudança no gênero dos pesquisadores brasileiros, percebe-se ainda que as pesquisadoras no Brasil ainda são minoria entre: 1) os pesquisadores premiados com a bolsa de produtividade do CNPq; 2) os pesquisadores-líderes de grupos de pesquisa; 3) os pesquisadores nomeados para os comitês assessores das agências de fomento; 4) os docentes nomeados para cargos de chefias; e 5) os nomeados para a Academia Brasileira de Ciências.

Perfil semelhante também é observado entre as cientistas francesas. Elas recebem 39,6\% das bolsas concedidas pelo Ministério da Pesquisa da França, mas também são minoria: 1) entre os professores titulares, cargo no mais alto nível hierárquico na academia; 2) nos comitês científicos e na academia de ciência; e 3) na academia de tecnologia. Vê-se aqui que, apesar da tradição, as cientistas francesas também têm chances pequenas para ascender profissionalmente.

$\mathrm{O}$ fenômeno que se refere às possibilidades remotas que as mulheres têm de ascender profissionalmente, de assumir maiores responsabilidades, de obter reconhecimento e também qualificações mais especializadas foi denominado, por Margaret Rossiter, na década de 1980, de segregação hierárquica (SCHIENBINGER, 2001). Para a atividade científica, diversos estudos têm buscado fatores que expliquem tal fenômeno. Entre eles, destacam-se: 1) a falta de controle emocional das mulheres, o que as fazem menos resistentes às pressões freqüentes dos cargos de comando; 2) a forma como as mulheres são educadas, que não lhes favorece o desenvolvimento do fator agressividade, fundamental nos cargos de chefia; e 3) as estruturas das instituições acadêmicas e científicas, dominadas por homens, fato que reforça o estereótipo masculino como o único apto a assumir tais cargos e posições. Vale dizer que segregação hierárquica não é exclusividade do Brasil e da França. Dados da National Science Foundation (NSF, 1996), importante agência financiadora da ciência norte-americana, mostram que a representação de mulheres nas universidades dos EUA também cai conforme elas progridem nos níveis acadêmicos: em 1995, elas representavam cerca de 46\% entre os instrutores, $35 \%$ entre os professores assistentes, 25\% entre os professores associados e $11 \%$ entre os professores titulares, aqueles de maior prestígio e reconhecimento entre os pares. $\mathrm{Na}$ Alemanha, país com tradição científica semelhante à da França, em 1998, as mulheres representavam 28,9\% $\mathrm{da}$ força de trabalho nas universidades e faculdades. Essa fração cai para 9,5\% e $5,9 \%$, respectivamente, entre os docentes (equivalente aos professores adjuntos) e os docentes $\mathrm{C} 4$, cargo de maior hierarquia no modelo alemão (Costa, 2002). Esse quadro caracteriza o que, na literatura sobre gênero, usualmente denomina-se "teto de cristal".

Rossitier também destaca outro tipo de segregação, a territorial, que, segundo ela, refere-se à concentração de mulheres em algumas poucas disciplinas (SCHIENBINGER, 2001). Apesar das mudanças no perfil da força de trabalho, de forma geral, as mulheres ainda predominam naquelas profissões de menor remuneração. Nas atividades acadêmica e científica, as mulheres tendem a concentrar-se nas ciências ditas "soft", ciências da vida (biológicas e da saúde), humanas e sociais; enquanto as ciências ditas "hard" são ocupadas prioritariamente por homens (Tabela 4). 
Tabela 4: Distribuição dos professores-pesquisadores e pesquisadores de onstituições de C\&T no Brasil e na França por grandes áreas do conhecimento (2004)

\begin{tabular}{|c|c|c|c|c|c|}
\hline \multicolumn{3}{|c|}{ Brasil (1) } & \multicolumn{3}{|c|}{ França (2) } \\
\hline Grande Área & $\begin{array}{c}\text { Total de } \\
\text { pesquisadores }\end{array}$ & $\begin{array}{c}\% \\
\text { Mulheres } \\
\end{array}$ & Grande área & $\begin{array}{c}\text { Total de } \\
\text { pesquisadores }\end{array}$ & $\begin{array}{c}\% \\
\text { Mulheres }\end{array}$ \\
\hline Ciências agrárias & 6.962 & $\begin{array}{c}32,6 \\
(2.273) \\
\end{array}$ & Ciências da vida & 12.116 & 41 \\
\hline Ciências biológicas & 8.069 & $\begin{array}{c}51,3 \\
(4.143) \\
\end{array}$ & $\begin{array}{l}\text { Medicina e } \\
\text { odontologia }\end{array}$ & 6.801 & 26 \\
\hline \multirow[t]{2}{*}{ Ciências da saúde } & \multirow[t]{2}{*}{8.941} & \multirow{2}{*}{$\begin{array}{c}53,0 \\
(4.735) \\
\end{array}$} & Química & 4.931 & 29 \\
\hline & & & Física & 4.314 & 19 \\
\hline Ciências exatas & 8.213 & $\begin{array}{c}30,2 \\
(2.482) \\
\end{array}$ & $\begin{array}{l}\text { Ciências do } \\
\text { universo }\end{array}$ & 2.800 & 23 \\
\hline $\begin{array}{l}\text { Engenharias e } \\
\text { ciências da } \\
\text { computação }\end{array}$ & 8.427 & $\begin{array}{r}23,3 \\
(1.967)\end{array}$ & Engenharia & 3.558 & 16 \\
\hline CTIC $(*)$ & ND & ND & CTIC $(*)$ & 6.845 & 19 \\
\hline Matemática & ND & ND & Matemática & 3.630 & 20 \\
\hline $\begin{array}{l}\text { Lingüística, Letras e } \\
\text { Artes }\end{array}$ & 2.592 & $\begin{array}{c}64,8 \\
(1.679) \\
\end{array}$ & ND & ND & ND \\
\hline Ciências sociais & 4.862 & $\begin{array}{c}41,1 \\
(2.012)\end{array}$ & Ciências sociais & 8.941 & 33 \\
\hline Ciências humanas & 8.172 & $\begin{array}{c}56,4 \\
(4.608)\end{array}$ & $\begin{array}{l}\text { Ciências } \\
\text { humanas }\end{array}$ & 12.545 & 45 \\
\hline Total & 56.238 & $\begin{array}{c}42,5 \\
(23.899)\end{array}$ & Total & $66.481(* *)$ & 31 \\
\hline
\end{tabular}

Fonte: Brasil: (1) CNPq, Diretório de Grupos de Pesquisa, 2004; França: (2) Relatório OST, 2004. (*) Ciência e tecnologia da informação e da comunicação; (**) Esses dados abrangem os pesquisadores dos nove institutos de pesquisa, assim como os professores-pesquisadores das universidades, ou seja, a quase totalidade dos envolvidos na pesquisa pública francesa; ND = Não disponível.

Vários estudos têm buscado identificar os motivos que levam mulheres a não ocuparem os cargos de chefia e de maior hierarquia na academia (segregação hierárquica) e os que as levam a concentrarem-se em determinadas áreas do conhecimento (segregação territorial). No Brasil, Velho e Leon (1998) realizaram um estudo quanti-qualitativo com docentes de quatro unidades da Universidade Estadual de Campinas/UNICAMP. As autoras mostraram que as mulheres dos institutos analisados avançam lentamente na carreira científica, dado associado ao modelo de cientista e/ou de ciência que elas assumiram em suas carreiras. Segundo as 
autoras, em áreas nas quais as mulheres conseguiram atingir massa crítica, poucas seguiam o modelo masculino de "fazer ciência", ou seja, modelo estereotipado de ciência, no qual o cientista (homem) abre mão do convívio social e/ou da família para dedicar-se integralmente à atividade científica. Essas cientistas, ao mesmo tempo em que parecem ressentir-se das barreiras para ascender no trabalho, priorizam a familia, os filhos e as responsabilidades com a casa, caracterizando o que Velho e Leon chamam de "modelo feminino de ciência”. Já naquelas áreas em que elas ainda são minoria e, portanto, nas quais há forte pressão dos pares masculinos, elas assumem um "modelo masculino" como estratégia para "sobreviver" à competição.

Estudos como esse mostram, por um lado, a complexidade das questões envolvidas nessa temática e, por outro, sinalizam a necessidade de políticas públicas direcionadas, que visem minimizar algumas dessas diferenças.

\section{As políticas públicas e ações afirmativas}

Uma das instituições pioneiras a incentivar a realização de estudos, pesquisas e conferências sobre a participação das mulheres no campo da ciência e tecnologia foi a UNESCO. Desde a década de 70, a UNESCO vem financiando diversos estudos e eventos internacionais sobre essa temática. Já na Conferência Geral de 1978, na qual foi aprovada uma recomendação sobre normalização dos indicadores de C\&T, os membros da UNESCO recomendaram explicitamente a utilização da variável "sexo". Desde então, foram inúmeras as iniciativas dessa instituição no sentido de promover a discussão sobre as mulheres na ciência. Destaca-se aqui a $1^{\text {a }}$ Conferencia Mundial sobre a Mulher, realizada em 1995, em Beijing (China), que teve como eixo central a constatação de que as discriminações sofridas pelas mulheres, inclusive na atividade científica, são um entrave ao desenvolvimento mundial ${ }^{11}$.

A Europa tem sido palco de diversas políticas públicas e ações afirmativas visando minimizar as diferenças entre homens e mulheres em relação à entrada e ascensão na ciência. Entre as ações mais recentes, destacam-se: 1) o relatório sobre as disparidades entre homens e mulheres ${ }^{12}$; 2) os programas - quadros comunitários $^{13}$; 3) a Unidade Mulheres e Ciência, criada junto à Direção de Pesquisa da Comissão Européia; 4) o Espaço Mulheres e Ciência no sexto programabásico (ciência e sociedade); 5) o Relatório do Grupo de Helsinki ${ }^{14}$; e 6) a Plataforma Européia das Mulheres Científicas, que, embora esteja em fase de concepção para a sua viabilização, já integra o item 24 da Ação "Plan Science and Society 2002" da Comissão Européia e tem como objetivo integrar, em rede, as mulheres científicas e as associações orientadas à busca da igualdade dos gêneros na pesquisa científica.

Como país representante da Comissão Européia, a França beneficiou-se de todas essas ações. Mas não somente isso, o país também elaborou diversas medidas e ações afirmativas para estimular a entrada e ascensão de mulheres nas diversas atividades econômicas. Especialmente na carreira científica, a criação do "Prêmio da Vocação C\&T das Mulheres”, em 1991, marca o início das políticas francesas voltadas exclusivamente para essa atividade (Quadro 1).

Já no Brasil (Quadro 2), o que se observa são medidas e políticas afirmativas 
voltadas para questões macro em torno da desigualdade de gênero: o planejamento familiar, a saúde da mulher, o cuidado dos filhos, os direitos dos empregados domésticos, a participação política das mulheres, a violência doméstica e a proteção das trabalhadoras. Para Pena e Pitanguy (2003), essas iniciativas têm sido o instrumento principal para a expansão das oportunidades e direitos das mulheres brasileiras. Segundo as autoras, esforço maior, no entanto, deve ser empreendido na mudança de expectativas da sociedade com relação ao que homens e mulheres deveriam ou não fazer e como deveriam ou não se comportar.

\section{Quadro 1: Principais medidas e ações afirmativas na França desde 1990}

\begin{tabular}{|c|c|c|}
\hline \multirow{8}{*}{ França } & 2004 & $\begin{array}{l}\text { Serviço dos direitos das mulheres e da igualdade. Vinculado ao Ministro } \\
\text { do Emprego, do Trabalho e da Coesão Social, tem com objetivo fazer da } \\
\text { igualdade entre mulheres e homens um dos eixos da modernização da vida } \\
\text { pública e da sociedade. }\end{array}$ \\
\hline & 2001 & $\begin{array}{l}\text { Jaune Budgétaire. Projeto de lei das finanças que apresenta em seu anexo } \\
\text { "créditos que concorrem às ações a favor dos direitos das mulheres". }\end{array}$ \\
\hline & 2001 & $\begin{array}{l}\text { Missão para a paridade na pesquisa. A missão define e coordena o conjunto } \\
\text { das medidas visando favorecer a igualdade entre mulheres e homens na } \\
\text { formação/estudos e nas carreiras de caráter científico. }\end{array}$ \\
\hline & 2001 & $\begin{array}{l}\text { Portaria n }{ }^{\circ} 1.156 \text {, de } 20 \text { de dezembro de 2001, sobre ações afirmativas do } \\
\text { Ministério da Justiça. Garante às mulheres } 20 \% \text { dos cargos de direção e } \\
\text { assessoramento superior, nas contratações de empresas prestadoras de serviços, } \\
\text { bem como de técnicos e consultores no âmbito dos projetos desenvolvidos } \\
\text { em parceria com organismos internacionais. }\end{array}$ \\
\hline & 2000 & $\begin{array}{l}\text { A Convenção para a promoção da igualdade de oportunidades. Visa } \\
\text { definir uma política global de igualdade de oportunidades entre os sexos } \\
\text { envolvendo todos os seus atores, do pré-elementar ao ensino superior, da } \\
\text { formação inicial à formação contínua ao longo da vida. }\end{array}$ \\
\hline & 2000 & $\begin{array}{l}\text { Missão igualdade/paridade. Associada ao diretor de ensino escolar, essa } \\
\text { missão visa favorecer a realização e o acompanhamento das ações relativas à } \\
\text { igualdade entre moças e moços, homens e mulheres junto ao Ministério da } \\
\text { Educação Nacional. }\end{array}$ \\
\hline & 1999 & $\begin{array}{l}\text { Prêmio l'Oréal. Esse programa recompensa cinco eminentes pesquisadoras } \\
\text { dos cinco continentes; ajuda jovens pesquisadoras com talento a darem } \\
\text { continuidade a suas pesquisas em ciências da vida, mais freqüentemente fora } \\
\text { de seus países de origem ( } 15 \text { bolsas). }\end{array}$ \\
\hline & 1991 & $\begin{array}{l}\text { Prêmio da Vocação C\&T das Mulheres. Prêmio concedido pelo Ministério } \\
\text { delegado para a paridade e a igualdade profissional, facilita o acesso das jovens } \\
\text { à ciência, particularmente das alunas do último ano do ciclo secundário. }\end{array}$ \\
\hline
\end{tabular}




\section{Quadro 2: Principais medidas e ações afirmativas no Brasil desde 1988}

\begin{tabular}{|c|c|c|}
\hline & 2006 & $\begin{array}{l}\text { Promulgação da Lei } 11.340 \text { (lei Maria da Penha). Torna mais rigorosa a punição } \\
\text { dos agressores de mulheres e aumenta os direitos e a proteção das vítimas. }\end{array}$ \\
\hline & 2006 & $\begin{array}{l}\text { Lançamento do Sistema Nacional de Informações de Gênero. Desenvolvido } \\
\text { pela SPM, contém indicadores que oferecem uma leitura dos microdados censitários } \\
\text { (1991 e 2000) sob a ótica de gênero e cor/raça Disponível em: < http://200.130.7.5/ } \\
\text { spmu/SNIG/snig.html> }\end{array}$ \\
\hline & 2006 & $\begin{array}{l}\text { "Pensando gênero e ciências". Encontro nacional de núcleos e grupos de pesquisa, } \\
\text { que ocorreu em Brasília, entre os dias } 29 \text { e } 31 \text { de março. }\end{array}$ \\
\hline & 2005 & $\begin{array}{l}\text { Dia internacional da não violência contra as mulheres (25 de novembro). } \\
\text { Articulação da campanha em nível nacional, com } 16 \text { dias de ativismo da não violência } \\
\text { contra as mulheres. }\end{array}$ \\
\hline & 2005 & $\begin{array}{l}\text { Lançamento do Programa Mulher e Ciência. Organizado pela SPM e pelo } \\
\text { CNPq para estimular a produção e difusão do conhecimento científico sobre gênero, } \\
\text { mulheres e feminismos. }\end{array}$ \\
\hline & 2004 & $\begin{array}{l}\text { Ciência Mulher: mulheres latino-americanas nas ciências exatas e da vida. } \\
\text { Conferência internacional organizada pelo CBPF, que contou com apoio do CNPq, } \\
\text { FINEP, FAPERJ e outras instituições. Realizada nos dias } 17 \text { e } 19 \text { de novembro, no } \\
\text { Rio de Janeiro. }\end{array}$ \\
\hline & 2004 & $\begin{array}{l}\text { Lei n }{ }^{\circ} \text { 10.745. Institui o ano de } 2004 \text { como o Ano da Mulher. Realização da } \\
\text { I Conferência Nacional de Políticas para as Mulheres, que lançou o Plano Nacional } \\
\text { de Políticas para as Mulheres, com } 239 \text { diretrizes consubstanciadas em } 199 \text { ações. }\end{array}$ \\
\hline & 2003 & $\begin{array}{l}\text { Criação da Secretaria Especial de Políticas para as Mulheres. Vinculada à } \\
\text { Presidência da República. (<www.presidencia.gov.br/estrutura_presidencia/sepm/>) }\end{array}$ \\
\hline Brasil $^{15}$ & 2003 & $\begin{array}{l}\text { Projeto de lei } \mathbf{n}^{\circ} \mathbf{2 9 3 / 2 0 0 3} \text {. Dispõe que } 30 \% \text { (trinta por cento) das vagas dos } \\
\text { concursos de ingresso na Brigada Militar serão destinadas para mulheres. }\end{array}$ \\
\hline & 2002 & 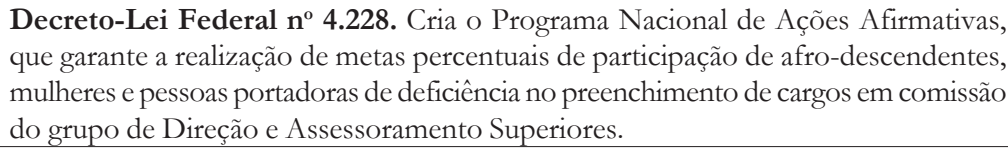 \\
\hline & 2001 & $\begin{array}{l}\text { Portaria } \mathbf{n}^{0} \mathbf{1 . 1 5 6} \text { do Ministério da Justiça. Cria o Programa de Ações Afirmativas } \\
\text { do Ministério da Justiça, que tem como objetivo central a incorporação, no cotidiano } \\
\text { do ministério, de um conjunto de medidas preconizadas pelo Programa Nacional de } \\
\text { Direitos Humanos, especialmente as referentes à promoção e proteção dos direitos } \\
\text { dos afro-descendentes, das mulheres e das pessoas portadoras de deficiência. }\end{array}$ \\
\hline & 1996 & $\begin{array}{l}\text { Programa Nacional dos Direitos da Mulher e o documento Estratégias da } \\
\text { Igualdade. Lançado pelo governo federal, busca traçar diretrizes para o uso de } \\
\text { ações afirmativas em relação às mulheres. }\end{array}$ \\
\hline & 1996 & $\begin{array}{l}\text { Prêmio Claudia. Desde 1996, a revista Claudia consulta uma rede de formadores de } \\
\text { opinião, entidades governamentais e não-governamentais, fundações e universidades } \\
\text { de todo o País em busca de indicações de mulheres extraordinárias em diversas áreas } \\
\text { de atuação. }\end{array}$ \\
\hline & 1995 & $\begin{array}{l}\text { Lei } \mathbf{n}^{\circ} \mathbf{9 . 1 0 0} \text {, art. } 11, \mathbb{S} 3^{\circ} \text {. Com o compromisso de incrementar a participação da } \\
\text { mulher nos processos decisórios, o governo brasileiro assegura a obrigatoriedade da } \\
\text { quota mínima de } 20 \% \text { de mulheres candidatas aos cargos legislativos nas eleições } \\
\text { municipais de } 1996 \text {. }\end{array}$ \\
\hline & 1988 & $\begin{array}{l}\text { Carta Constitucional do Brasil. Consagra o princípio da igualdade. Apesar de } \\
\text { decantada a igualdade formal, o próprio texto da Lei Maior prevê normas que } \\
\text { concedem tratamento diferenciado entre homens e mulheres. }\end{array}$ \\
\hline
\end{tabular}


Em relação à atividade científica, o que se observa são ações mobilizadoras, ainda tímidas, promovidas por instituições isoladamente e/ou pela Secretaria Especial de Políticas para as Mulheres (SPM). Por conta disso, observa-se que, por exemplo, em diversos comitês de avaliação de agências federais de fomento à pesquisa, $\mathrm{O}$ número de mulheres é quase nulo.

\section{Discussão e sugestões}

Em que pese o aumento contínuo do ingresso de mulheres na educação, no mercado de trabalho e nas atividades científicas, as estatísticas mostradas revelam que, mesmo em países com distintas histórias e tradições na ciência, tais como o Brasil e a França, as mulheres ainda estão sub-representadas em algumas áreas e pouco avançam em cargos e posições de maior destaque e reconhecimento no meio acadêmico e científico.

Mitos, preconceitos, discriminações, o que está por trás do teto de cristal? Os números certamente não dão conta de responder a essa questão, mas fornecem medidas objetivas do status das mulheres na ciência, em particular, nesses dois países: elas ainda estão em desvantagem em um sistema controlado predominantemente por homens. As causas para tamanhas diferenças e discrepâncias são muito complexas e envolvem múltiplos fatores, sejam de ordem social, cultural e econômica. Essa temática tem sido estudada por diversos autores ${ }^{16}$. Em um dos estudos pioneiros, foi amplamente discutida e analisada por Alice Rossi (1965), que mostrou participação muito reduzida de mulheres nas atividades de C\&T nos EUA, nos anos de 1950 e 1960, variando de $1 \%$ do total de empregados nas engenharias até $27 \%$ na biologia. Diante desse quadro, a autora discute o peso de alguns aspectos sociais e/ou psicológicos, que poderiam explicar a baixa participação de mulheres em C\&T naquele país. São eles: 1) a prioridade do casamento e da maternidade diante da escolha profissional; 2) a influência dos pais na escolha da carreira de seus filhos, determinando o que devem ser atitudes e comportamentos "femininos" e "masculinos"; e 3) incompatibilidades ou diferenças de cunho biológico e/ou social entre homens e mulheres, tais como de habilidades cognitivas e nas questões da independência, da persistência e do distanciamento do convívio social.

Passados mais de 30 anos, esses mesmos aspectos foram identificados nas respostas de algumas cientistas de uma importante universidade pública brasileira, quando questionadas sobre seus perfis de produtividade e a sub-representação de mulheres em determinadas áreas e cargos (Velho; Leon, 1998). Com base nas entrevistas, as autoras discutem a construção social da ciência como ponto importante para o entendimento de tais diferenças. As imagens estereotipadas de cientistas, a concentração de mulheres em determinadas áreas e a escassez delas em outras, assim como sua baixa participação em cargos administrativos ou de chefia e em cargos de maior reconhecimento acadêmico, não podem ser explicadas sem que se leve em conta o fato de que são conceitos construídos pela sociedade em que vivemos e nos cercamos.

A busca (para o Brasil) e a manutenção (para a França) do desenvolvimento econômico tem cada vez mais relação com o investimento massivo em setores como educação e C\&T. Portanto, torna-se fundamental estimular que metade da nossa força de trabalho participe ativamente desses setores estratégicos para o País. A 
França vem tomando medidas para estimular a participação e ascensão das mulheres no sistema de C\&T (Quadro 1). No Brasil, essa discussão ainda parece "engatinhar".

Mudanças nesse quadro dependem, entre outros fatores, de ampla campanha de divulgação, que passe por todo o sistema educacional - do ensino fundamental à universidade -, pela indústria e pelo governo, visando minimizar as diferenças entre meninos e meninas, mostrando que ambos não apenas têm direitos no plano legal, mas também no social de escolha e de igualdade em todos os campos do conhecimento.

(Artigo recebido em novembro de 2006. Versão final em dezembro de 2006)

\section{Notas}

* Não se nasce mulher, torna-se uma.

${ }^{1}$ Para detalhes, sugere-se a leitura de Harding (1987) e Pnina (1996).

${ }^{2}$ Fonte: Estatísticas do Século XX - IBGE (2002) e PNAD 1999 a 2004. Disponível em: <www.ibge.gov.br>. Acesso em: 27/11/2006.

${ }^{3}$ Disponível em: <http://www.insee.fr>. Acesso em: 06/12/2006.

${ }^{4}$ A prestigiosa EP foi criada em 1794 pela "Convenção Nacional” no período da Revolução Francesa. Uma comissão foi instituída para criar uma escola central voltada às obras públicas. A escola não era militar e recebeu o nome de École Polytechnique em 01/09/1795. Napoleão $1^{\circ}$, por decreto de 16/07/1804, submete a EP ao regime militar.

${ }^{5}$ Disponível em: < http://www.historia.presse.fr/data/mag/653/65301601.html>. Acesso em: 10/01/2004.

${ }^{6}$ Estatísticas do Século XX e Indicadores sociais 1999 a 2004 (IBGE). Acesso em: 27/11/2006

${ }^{7}$ Instituto Nacional de Estudos e Pesquisas Educacionais. Sinopse 2002 Atualizada. Brasília: INEP, 2002.

${ }^{8}$ Disponível em: <http://www.recherche.gouv.fr>. Acesso em: 06/12/2006.

${ }^{9}$ Op. cit. IBGE (2004): Estatísticas do Século XX - IBGE. Dados sobre a educação - Tabela 5.1.5.2.4 - Cursos existentes, matrícula no início do ano, matrícula e conclusões no ano anterior, no ciclo profissional, segundo o sexo, por áreas e ramos de ensino - 1972. Acesso em: 27/11/2006.

${ }^{10}$ Disponível em: <http://www.abc.org.br/>. Acesso em12/12/2006.

${ }^{11}$ Para detalhes sobre o papel da UNESCO na discussão sobre a participação das mulheres na ciência, sugere-se a leitura de Tabak (2002).

${ }^{12}$ Constituído pela Comissão Européia em resposta a uma demanda do Conselho Europeu, na primavera de 2003. Um dos objetivos fixados consiste, de fato, em assegurar uma proporção de mulheres ativas que passe de 53\% para 60\% até 2010. Atualmente, somente cinco países da União Européia atingem esse objetivo de 60\%. São eles: a Dinamarca, a Finlândia, os Países Baixos, a Suécia e o Reino Unido.

${ }^{13}$ Visa aumentar a participação das mulheres nos programas da Comissão Européia de pesquisa, promovendo suas candidaturas e, ao mesmo tempo, mantendo o princípio de excelência. O objetivo 
geral de 40\% de mulheres foi fixado para o programa Marie-Curie, nas assembléias consultivas e nos painéis de avaliação.

${ }^{14}$ Elaborado em 1999, ele recomendava, de fato, nas suas conclusões, levar em consideração, de modo sistemático, a questão de gênero em todos os níveis para promover e atingir a igualdade, responder a uma demanda crescente de dados pertinentes e fornecer regularmente dados harmonizados e comparáveis a fim de dar sustentação aos debates e tomadas de decisões, medir o impacto das políticas em matéria de gênero, de igualdade de oportunidades e de paridade.

${ }^{15}$ DiAs, M B. Ações afirmativas: uma solução para a desigualdade. Revista Del Rey, n. 4, p. 24-25, dez. 1998.

${ }^{16}$ Detalhes sobre essa discussão poderão ser encontrados nas referências: Schienbinger (2001), Soares (2001), Hanson (1996), Morse (1995), Stolte-Heiskanen (1991) e Nature Debates.

\section{Referências bibliográficas}

BEN-DAVID J. Scientific productivity and academic organization in nineteenth-century medicine. American Sociological Review, n. 25 p. 828-843, 1960.

Costas, I. Women in Science in Germany, Science in context. p.557-576, 2002.

Hanson, S.L. Lost talent: women in the sciences. Philadelphia: Temple University Press, 1996.

Harding, S.; O'barr J. (eds.) Sex and scientific inquiry, Chicago: University of Chicago Press, 1987.

Instituto Brasileiro de Geografia E Estatística. Estatísticas do Século XX - IBGE. Disponível em: <www.ibge.gov.br>. Acesso em: 27 nov. 2006.

Morse, M. Women changing science. New York: Plenum Press, 1995.

National Science Foundation. Women, minorities, and persons with disabilities in Science and Engineering. Arlington: NSF, 1996.

Nature Debates. Disponível em: <www.nature.com/nature/debates/>. Acesso em: 06 dez. 2006.

Pena, M.V. J.; Pitanguy, J. A questão de gênero no Brasil. Brasília: Banco Mundial/Departamento de Políticas Econômicas e Redução da Pobreza, 2003. Disponível em: <http:// www.cepia.org.br/Textos_online/textos_online.html>. Acesso em: 28 nov.2006.

PNINA, G. Women in modern scientific research: a historical view. In: The gender dimension of science and technology. Paris: UNESCO, 1996. (World Science Report). Disponível em: <http://www.unesco.org/science/publication/eng_pub/gender.htm>. Acesso em: 28 nov.2006.

Rossi, A.S. Women in science: why so few? Social and psychological influences restrict women's choice and pursuit of careers in science. Science, n.148, p. 1196-1202, 1965.

SCHIEnBinger L. O feminismo mudou a ciência? Bauru: EDUSC, 2001. 
Schwartzman, S. Struggling to be born: the scientific community in Brazil. Minerva, v. XVI, n. 4, p. 545-580, 1978.

SOARES, T.M. Mulheres em ciência e tecnologia: ascensão limitada. Química Nova, n. 24, p. 281-285, 2001.

Stepan, N. Gênese e evolução da ciência brasileira. Rio de Janeiro: Artenova, 1976.

Stolte-Heiskanen, V. Women in science. Token women or gender equality? Paris: International Social Science Council / Unesco, 1991.

TABAK, F. O laboratório de Pandora - estudos sobre a ciência no feminino. Rio de Janeiro: Garamond, 2002.

Teixeira, Z.A. As mulheres e o mercado de trabalho. Artigo publicado e disponível em: <http://www.universiabrasil.net/materia_imp.jsp?id-3010>. Acesso em: 28 nov.2006. Velho, L.; LeOn, E. A construção social da produção científica por mulheres. Cadernos Pagu, n. 10, p. 309-344, 1998.

\section{Bibliografia complementar}

AbIr-Am, P.G.; Outram, D, (eds.). Uneasy careers and intimate lives. Women in Science, 1789-1979, New Brunswick: Rutgers University Press, 1989.

Beauvoir, S. de. O segundo sexo. $8^{\text {a }}$ Ed. Rio de Janeiro: Nova Fronteira, 1991.

Centre National de la Recherche Scientifique. Les femmes dans l'bistoire du CNRS. Paris: CNRS, 2004.

Clair, R. (ed.). La formación científica de las mujeres. ¿Por qué hay tan pocas científicas? Madrid: Los Libros de la Catarata, 1996.

Goff, A.C. Women can be engineers. Ann Arbor/Michigan, 1946.

Herzenberg, C. Women scientists from antiquity to the present. West Cornwall: Locust Hill Press, 1986.

Levy-Leblond, J.M.; Jaubert, A. (Auto) critique de la science.In : Les femmes. Capítulo 8, p. 282-297. Pais: Seuil, 1975

Opfell, O.S. The lady laureates: the women who have won the Nobel Prize. Metuchen: Scarecrow Press, 1986.

PoIrIER, J.P. Histoire des femmes de science en France - du Moyen Age à la Révolution. Paris: Pygmalion, 2002. 


\section{Resumo - Resumen - Abstract}

As mulheres na pesquisa, no desenvolvimento tecnológico e na inovação: uma comparação Brasil/França

Pierre Ohayon, Jacqueline Leta, Martine Carisey e Patrick Séchet

Este estudo analisa e compara o espaço conquistado pelas mulheres nas atividades de C\&T em dois países, a França e o Brasil, que diferem não apenas nas dimensões demográficas e econômicas, mas também nas suas tradições científicas. Assim, as respectivas estatísticas, bem como as ações e medidas legislativas para estimular a inserção de mulheres na atividade científica, são apresentadas, discutidas e contextualizadas à luz da história da institucionalização da ciência nos dois países.

Palavras-chave: ciência e gênero; pesquisa; desenvolvimento tecnológico; indicadores França/ Brasil.

Las mujeres en la investigación científica, en el desarrollo tecnológico y en la inovación: una comparación Brasil/Francia

Pierre Ohayon, Jacqueline Leta, Martine Carisey y Patrick Séchet

Este trabajo analiza y compara el espacio conquistado por las mujeres en actividades de ciencia y tecnología en dos países, Francia y Brasil, diferentes no sólo en las dimensiones demográficas y económicas, como también en sus tradiciones científicas. Así, las respectivas estadísticas y las acciones y medidas legislativas para estimular la inserción y participación de mujeres en la actividad científica son presentadas, discutidas y contextualizadas a la luz de la historia de la institucionalización de la ciencia en los dos países.

Palabras clave: ciencia y género; investigación; desarrollo tecnológico; indicadores Francia/ Brasil.

\section{Women in research, technology development and innovation: a comparison between Brazil and France}

Pierre Ohayon, Jacqueline Leta, Martine Carisey and Patrick Séchet

This paper analyzes and compares the space women have conquered in science and technology activities in two countries, France and Brazil. These countries differ not only in their demographic and economic dimensions, but also in their scientific traditions. Thus, their respective statistics, as well as their actions and legislative measures to stimulate women's participation in scientific activities, are presented, discussed, and contextualized in light of the history of institutionalization of science in both countries.

Key words: science and gender; research; technology development; indicators France/Brazil.

Agradecimentos

Os autores agradecem pelas valiosas contribuições trazidas por Cláudia Yukari Asazu, Larissa Mamed Hori e Mônica Rique Fernandes para o aprimoramento do artigo 